\title{
VIOLÊNCIA MÍTICA E VIOLÊNCIA DIVINA EM WALTER BENJAMIN
}

Edson Sá dos Reis

\begin{abstract}
A institucionalização do direito é institucionalização do poder, e, nesse sentido, um ato de manifestação imediata da violência. A justiça é o princípio de toda instituição divina de fins, o poder (Macht) é o princípio de toda institucionalização mítica do direito.
\end{abstract}

Walter Benjamin

\section{RESUMO}

Este trabalho tem como objetivo a exposição do conceito de Estado como violência (Gewalt), baseada no pensamento teórico do filósofo Walter Benjamin (1892-1940) em seu ensaio "Zur Kritik der Gewalt (Crítica da violência, Crítica do poder) de 1921, no qual o filósofo expõe que o sistema jurídico, em que o Estado se apoia, tem na sua base a violência mítica como instauradora e mantenedora do Direito.

Palavras-chave: Poder, violência, estado, mera vida, direito.

\section{MYTHICAL VIOLENCE AND DIVINE VIOLENCE IN WALTER BENJAMIN}

\begin{abstract}
This paper aims to show the concept of State as violence (Gewalt), based on the theoretical thinking of the philosopher Walter Benjamin (1892-1940) in his essay "Zur Kritik der Gewalt (Critique on violence, critique on power) of 1921 in which the philosopher states that the legal system, in which the State is based, has its basis on the mythical violence as establisher and maintainer of Law.
\end{abstract}

Keywords: Power, violence, state, mere life, law. 
Para estabelecer uma visão da realidade atual, a crítica à violência torna-se imprescindível, pois o fenômeno da violência é um acontecimento que permeia não só toda nossa realidade, mas toda a história humana.

O ensaio escrito por Walter Benjamin em 1921, Para uma crítica da violência (Zur Kritik der Gewalt) é a fonte principal deste artigo, que tem como foco os conceitos: Violência Mítica, Violência Divina e Mera Vida. Visa-se pensar como os conceitos Violência Mítica e Violência Divina se contrapõem e como ambos agem sobre o que Benjamin chama de mera vida (blosses Leben).

A Violência (Gewalt) é pensada, inicialmente, como o cerne do poder vigente, levando em consideração que é por meio dela que o poder se mantém. A ordem de toda a sociedade é assegurada por meio da ameaça da Violência do Direito, que serve de escudo para toda ordenação social, contribuindo para que tudo continue como está. Posteriormente, na procura de suas bases metafísicas ela será reconhecida como Violência Mítica (die mytische Gewalt).

Em contraposição à violência exercida pelo direito, Benjamin conceitua a Violência Divina (die göttliche Gewalt), que não funda nenhuma forma de direito, e sim aniquila com todo o direito e sua violência. Enquanto a violência mítica terá caráter de direito, a violência divina será reconhecida como justiça. A pergunta, é, direito é o mesmo que justiça? Com base nessa interrogação tentaremos analisar a violência como fundamento do Direito e criadora da mera vida, sobre a qual o Direito se exerce. Simultaneamente faremos a contraposição da violência mítica com o que Benjamin chama de Violência Divina que aniquila o Direito e liberta o ser vivente.

\section{O CARÁTER DUPLO DA VIOLÊNCIA: INSTAURAÇÃO E MANUTENÇÃO DO DIREITO}

$\mathrm{Na}$ análise de Benjamin, a violência desempenha um papel duplo. Segundo o filósofo, ela é responsável pela instauração de toda ordenação do Direito, uma vez que apenas a violência pode instaurar o Direito e estabelecer o Poder (Macht). $\mathrm{O}$ segundo caráter da violência é a manutenção do Direito que ela estabeleceu. Ela desempenha o papel de manter o poder estabelecido. Dessa maneira, o Direito ${ }^{1}$ é

\footnotetext{
1 Para efeito de organização, sempre que a palavra Direito for escrita com $D$ maiúsculo estará se referindo a todo Direito. De modo que direitos individuais serão escritos com d minúsculo.
} 
visto não como uma instituição do Estado, mas como o próprio Estado em exercício de poder.

O direito de guerra é mostrado como o princípio no qual o Direito se funda. A violência exercida pela situação de guerra possui um caráter de violência instauradora do Direito. Tanto dentro das fronteiras do Estado como fora delas, a violência da guerra representa um caráter de instauração do Direito. Se a população se insurge contra uma forma de Estado e instala-se uma guerra civil, nesse caso o Direito pode cair e ser substituído por um novo. Se dois Estados entram em guerra, o foco é conquistar e instaurar um novo Direito. Aqui, a Violência possui um objetivo imediato, ou seja, de vencer o inimigo o mais depressa possível. Quando a guerra chega ao fim, então o vencedor subjuga o vencido e estabelece um novo Direito. Desta maneira, a instauração de um novo Poder é estabelecida pelo vencedor?.

A palavra "paz", quando correlata à "guerra", assinala apenas o ponto no qual um novo Direito é instaurado e sua continuidade parece garantir aquilo que é nomeado como "paz". Enquanto tudo estiver de acordo com o vencedor, isto é, conquistador, a "paz" continuará. A cerimônia de "paz" parece ser necessária, mesmo sem garantias de que o Direito estabelecido pela vitória continue, pois assinala a vitória e o controle do vencedor sobre os vencidos.

A primeira face da Violência demonstra aquele poder temido pelo Estado, ou seja, a instauração de um novo Poder. Assim, o Estado busca monopolizar a Violência para que não haja instauração de um novo Direito.

[...] o interesse do direito em monopolizar a violência com relação aos indivíduos não se explicaria pela intenção de garantir os fins de direito mas, isso sim, pela intenção de garantir o próprio direito; de que a violência, quando não se encontra nas mãos do direito estabelecido, qualquer que seja este, o ameaça perigosamente, não em razão dos fins que ela quer alcançar, mas por sua mera existência fora do direito. ${ }^{3}$

Com a atitude do monopólio da violência, o Direito demonstra o segundo caráter dela, apontado por Benjamin. A segunda face é a manutenção do Direito estabelecido. Desse modo a violência torna-se monopólio do Estado, pois como ferramenta de instauração do Direito, o Estado a teme por reconhecer sua utilidade.

\footnotetext{
2 Para um melhor desenvolvimento do assunto, deve-se ler o texto "Teses sobre o conceito de história" de 1940. Neste texto Benjamin elabora uma teoria da história a contrapelo e demonstra que toda história é vista pelo vencedor e não pelo vencido.

3 BENJAMIN, 2011, p. 127.
} 
Assim, a monopolização da violência reprime aqueles que buscam usá-la fora do Direito e este simples ato é uma das maiores ameaças existentes ao Poder do Direito. Por esta perspectiva, é a necessidade do Direito de manter-se no poder que gera a repressão violenta da população quando esta luta por melhores condições.

Face a esse problema, cria-se a necessidade de se manter o Poder a todo custo. Agindo assim, o Direito revela aquilo que, a nosso ver, mostra-se como o seu lado mais monstruoso - a institucionalização da violência em algumas instituições. Segundo Benjamin, o fenômeno de institucionalização da violência começa exatamente no direito militar obrigatório. A imposição da obrigatoriedade do militarismo tem como objetivo a aplicação da violência para fins de direito. Portanto, trata-se aqui da garantia de que o poder será conservado. Porém, não é apenas na instituição do exército que a violência institucionalizada se manifesta. Existe outra instituição e ainda mais macabra, se assim podemos dizer, que tem como objetivo sustentar as ordenações de direito e o poder do Estado. Esta apresenta-se como a corporação policial. Diz Benjamin:

Em uma mistura ainda mais contrária à natureza do que na pena de morte, numa espécie de mistura espectral, estes dois tipos de violência estão presentes em outra instituição do Estado moderno: a polícia. (...) O infame de uma tal instituição (...) reside no fato de que nela está suspensa a separação entre a violência que instaura o direito e a violência que o mantém. Da primeira exige-se sua comprovação pela vitória, da segunda, a restrição de não se propor novos fins. ${ }^{4}$

A violência institucionalizada da polícia está isenta das condições do Direito mostradas na citação acima, a primeira condição é a comprovação pela vitória, essa comprovação é o caráter de vencer uma guerra e propor uma nova ordem de Direito, e a segunda condição é a de não propor novos fins, ou seja, de não estabelecer novas regras. A polícia é usada em momentos de impotência do Estado e, portanto, seus métodos podem fugir do aval do mesmo em determinadas situações e podemos ter a impressão de que a instituição policial está agindo independente do Estado. Porém, esse aval é concedido pelo Estado para sua própria manutenção. Desse fenômeno se deduz o que há de mais monstruoso no Direito, a sua negação por uma de suas instituições, pois a polícia nega o Direito para sua manutenção.

\footnotetext{
${ }^{4}$ BENJAMIN, 2011, p. 135.
}

Edson Sá dos Reis - Graduação em Filosofia pela Universidade Estadual do Ceará (UECE), Brasileiro, residente em Fortaleza - CE, E-mail: uchiha_edson16@hotmail.com 
Um exemplo em que há negação do Direito, para mantê-lo na posse do poder, está situado nas manifestações ocorridas em 2013 no Brasil. Ali, vimos o batalhão de choque policial usar de métodos ilegais, ou seja, de práticas que estavam fora da lei, enquanto os poderes do Direito fechavam os olhos para as ações da corporação militar. Assim, o paradoxo do Direito aparece nessa impossibilidade de se manter, isto é, quando ele libera ações violentas que parecem agir de forma independente e que quebram com a própria ordem de legalidade do Direito. E não se pode deixar de ver nessa ação arbitrária da corporação militar, o prolongamento da força que caracteriza o Estado.

O paradoxo existente no Direito é constitutivo, portanto, aparece em várias esferas. Um outro exemplo desse fenômeno está na luta de classes, mais especificamente no direito de greve dos trabalhadores. A legalidade do direito de greve dos trabalhadores é também uma medida protetora do poder. Porém, ao contrário da violência institucionalizada da polícia, a greve é a forma pela qual a violência do Estado evita o enfrentamento com os trabalhadores. Portanto ela não é considerada como violência, pelo menos, em seu começo.

A greve torna-se violência quando toma o aspecto de chantagem, pois, em busca de direitos e mudança da ordenação social a favor dos trabalhadores, ela é um movimento contra a ordem vigente, porém, ainda fazendo parte dessa ordem, pelo fato de que ela não busca derrubar o Direito, mas conseguir reformas nos direitos do trabalho. Portanto, sob esse aspecto a greve pode ser considerada como violência, mas, em outro aspecto, a greve pode ser considerada como meio puro ${ }^{5}$. Reconhecida e institucionalizada sob a forma de lei, a greve é uma das violências paradoxais do Direito, pois o mesmo libera a prática para sua conservação.

Para explicitação da greve como violência e como não violência, Benjamin recorre aos conceitos de Georges Sorel ${ }^{6}$ sobre a greve política e a greve geral proletária. A greve política se caracteriza como a greve que visa reformas e não

\footnotetext{
${ }^{5}$ [...] Aos meios de toda espécie que estão em conformidade com o direito e àqueles que não estão - e que são, todos, violência - podem ser confrontados, como meios puros, os não - violentos." BENJAMIN, 2011, p. 139.

6 Georges Sorel (1847 - 1922) publicou vários artigos reunidos no livro Réflexions sur la violence (1907) no Brasil foi publicado pela editora vozes e chama-se Reflexões sobre a violência. Nele estão os conceitos de greve política e greve geral proletária, bem como outras teses.
} 
destruição do sistema vigente. A greve geral proletária possui o cunho revolucionário de aniquilação do sistema. Diz Benjamin:

\begin{abstract}
Enquanto a primeira forma de suspensão do trabalho é violenta, uma vez que provoca só uma modificação exterior das condições de trabalho, a segunda, enquanto meio puro, é não-violenta. Com efeito, esta não acontece com a disposição de retomar o trabalho depois de concessões superficiais ou de qualquer modificação das condições de trabalho, mas com a resolução de retomar apenas um trabalho totalmente transformado, sem coerção do Estado, uma subversão que esse tipo de greve não apenas desencadeia, mas leva sua completude. ${ }^{7}$
\end{abstract}

A primeira modalidade de greve, a política, visa a uma modificação exterior do trabalho, ou seja, medidas reformistas de instauração do direito, portanto, caracteriza-se como violência. A segunda medida, greve geral proletária, não chantageia, mas golpeia de forma a eliminar a participação do Estado e com isso, do Direito também, de forma que a volta ao trabalho ocorre apenas quando é cumprido o objetivo de eliminação total da violência utilizada pelo Estado sobre os trabalhadores.

A luz da reflexão de Benjamin sobre a violência, pode-se perceber que a crítica da violência está centrada no que aqui expomos como instauração e manutenção do Direito. A partir dos pontos mostrados, Benjamin expõe então a violência como cíclica, ou seja, o movimento histórico da sociedade humana como luta por poderes. Esse movimento visa à derrubada de um Poder e a instauração de outro e assim sucessivamente. Cabe, portanto, ir às bases metafísicas da violência e esclarecê-las para compreender o ciclo da violência, ou como o próprio Benjamin intitula, a violência mítica.

\title{
O MITO E A VIOLÊNCIA MÍTICA
}

O conceito de Mito (Mythos) em Benjamin está circunscrito a toda sua obra. Trata-se de um pensamento fundamental, para podermos prosseguir a exposição sobre a violência. O filósofo possui uma preocupação com este conceito já em seus primeiros escritos. Em 1916 Benjamin escreve um texto chamado "O significado da

\footnotetext{
7 BENJAMIN, 2011, p. 143.
}

Edson Sá dos Reis - Graduação em Filosofia pela Universidade Estadual do Ceará (UECE), Brasileiro, residente em Fortaleza - CE, E-mail: uchiha_edson16@hotmail.com 
linguagem no Drama Barroco e na Tragédia"8 e esboça o conceito de Mito associado ao nascimento da linguagem.

\begin{abstract}
$\mathrm{Na}$ tragédia, a palavra e a tragicidade se originam, simultaneamente, do mesmo lugar. $\mathrm{Na}$ tragédia, cada discurso é tragicamente decisivo. A pura palavra é imediatamente trágica. [...] A palavra torna-se trágica atuando de acordo com o puro significado de que ela própria é portadora. A palavra enquanto portadora pura de seu significado constitui a palavra pura. ${ }^{9}$
\end{abstract}

A origem do Mito ocorre concomitantemente com o nascimento da linguagem que cristaliza o mundo no círculo mágico de significados. De acordo com o significado, ou seja, cristalização da natureza na palavra, a linguagem é portadora da tragédia e a partir do ato de fechá-la no círculo, a história nasce como mito, ou podemos dizer, torna-se cíclica. Tal ação de congelamento da natureza faz com que recaia sobre o homem uma tragicidade que o ameaça. Linguagem, Tragédia, História e Direito são efeitos da significação fechada, em que a palavra enquanto linguagem trágica, aprisiona a natureza.

Quem significa a natureza é o homem e sob esta perspectiva ele parece livre do significado, porém, ao fechar o mundo em um círculo mágico congelado, o ser humano também se aprisiona. O homem, considerado por Benjamin a "coroa da criação", tenta libertar-se do mito na figura do herói trágico, porém, quando há a tentativa da quebra da significação cristalizada da natureza em forma de linguagem, ela recai sobre ele como destino trágico. Com perspicácia Benjamin nota que o homem está preso ao mito.

O Mito caracteriza-se como um círculo mágico da linguagem enquanto tragédia da significação cristalizadora e inescapável por seu caráter cíclico. Basta olharmos com atenção as tragédias gregas para termos a compreensão do destino (Schiksal) que o homem não pode vencer. Antígona, Édipo, Ájax e tantas outras tragédias, demonstram o caráter implacável do destino sobre os homens que ousaram levantar a cabeça contra o mito. $O$ destino trágico não visa à história, mas a manutenção do mito como história não arrebatadora, ou seja, manutenção do poder pelo destino que recai sobre os homens.

\footnotetext{
${ }^{8}$ Esse e outros textos que possuem ideias embrionárias do pensamento de Benjamin encontram-se no livro "O capitalismo como religião" lançado em 2013 no Brasil com textos inéditos do filósofo pela Editora Boitempo.

9 BENJAMIN, 2013, p. 65
}

Edson Sá dos Reis - Graduação em Filosofia pela Universidade Estadual do Ceará (UECE), Brasileiro, residente em Fortaleza - CE, E-mail: uchiha_edson16@hotmail.com 
Esclarecido o conceito de mito, cabe articulá-lo com o conceito de história como tradição dos vencedores. Se o mito exerce sobre o mundo uma paralisação trágica, a história aparece para nós como história mítica. A forma de todo processo histórico está descrita no círculo exposto até agora como luta por direitos. Não é a toa que Benjamin nos orienta à análise da história a contrapelo para podermos constatar que o que nos é repassado pela história tradicional é a versão dos vencedores.

A presença do mito na história se dá por meio da violência mítica. Em sua forma arquetípica a violência mítica é encontrada como manifestação dos deuses em autoafirmação de existência. Ao citar o mito de Níobe, o filósofo demonstra as intenções de Apolo e Ártemis, não em defender um direito já estabelecido, mas de instaurar um direito. Essa instauração demonstra uma vitória do destino sobre o homem. $\mathrm{O}$ orgulho com que Níobe desafia a deusa Leto não desafia um direito já fundado, mas uma esfera supra-humana onde o homem não pode vencer. $O$ resultado de tal desafio tem sua consequência na morte dos filhos de Níobe pelos filhos de Leto, que tem como consequência a instauração um novo direito.

A transgressão da mãe é punida com a morte dos filhos, porém, a punição de morte não recai sobre a criminosa, mas nos seus filhos que eram objeto de seu orgulho. Com o ato de punição, se caracteriza a manutenção do direito através da culpa pela morte dos filhos. Esse ato de punição é derivado de um julgamento, julgamento esse concretizado com o conhecimento do bem e do mal. Esse caráter do julgamento que, para Benjamin é sempre caótico, uma vez que é derivado do mito, é impresso no Direito. Com a punição mítica a culpa é introjetada e a ameaça do destino mantém os homens longe da transgressão da lei. Dessa maneira, a violência mítica dos deuses aparece como idêntica à violência do direito, pois ela funda e também mantém, a partir dos pressupostos metafísicos da culpa, da penitência e da ameaça, o direito dos deuses.

\footnotetext{
Em um profundo impulso de justiça de Esquilo (..) foi a tragédia que rompeu com o destino demoníaco (...) porque na tragédia o homem pagão percebe que é melhor que os deuses, e ao percebê-lo, perde o uso da palavra, condenando ao silêncio esse conhecimento (...) Esse silêncio do herói (...) coloca sob suspeita os perseguidores. ${ }^{10}$
}

\footnotetext{
${ }^{10}$ BENJAMIN, Origem do drama barroco alemão, p. 132. 
A culpa advém do ato judicante, onde o homem passa a ter aspiração de separar o Bem e o Mal. É o próprio conhecimento que torna o ser humano em culpado, pois nele, o homem desafia a ordem mítica querendo tornar-se igual aos deuses. Esse ato é em Benjamin, o fundamento da esfera do Direito. Nele, está, portanto, a gênese da culpa no homem, pois como diz Benjamin em carta a Carla Seligson de 04 de agosto de 1913: "Alle Erkenntnis ist Schuld, wenigstens alle Erkenntnis vom Guten oder Bösen - so sagt auch die Bibel'. ${ }^{11} \mathrm{O}$ conhecimento encontra papel fundamental como ponto central no julgamento do homem. Com o atrevimento de conhecer Bem e Mal o homem sai da linguagem nomeadora, desinteressada, que revela a essência espiritual das coisas e entra na linguagem judicante que transforma a linguagem em "tagarelice" ${ }^{12}$ e converte-se em poder.

A violência mítica coincide com a violência do Direito e instala a culpa e a ameaça e as introjeta em toda a sociedade para que o Direito não seja desafiado. Sua manutenção está baseada metafisicamente nesses pressupostos e sua determinação está na redução do homem à mera vida. Pode-se compreender como mera vida, a vida orgânica do homem enquanto simplesmente corpo e carente de todas as outras esferas humanas como racionalidade e paixões. Como mera vida, não há diferença alguma entre o homem, as plantas e os animais, pois carente de todas as outras esferas, ele é apenas corpo. Sob o conceito de mera vida a violência se exerce sobre o homem.

O homem enquanto simples ser vivente, ou seja, mera vida, é criado pela esfera do poder do Direito, tal criação assegura a dominação do Direito sobre o ser humano. Sem mera vida, não há como a ameaça do Direito se impor sobre o homem. O sangue é o símbolo do poder do Direito. Torna-se pressuposto que o Poder se exerça de modo aterrorizante e ameaçador para que não haja riscos de reincidência. Podemos traçar toda a história do direito pelo viés da violência exercida sobre o corpo humano como forma de imposição das regras vigentes na sociedade. Porém, há algum tipo de violência fora dos padrões do Direito positivo e natural, onde o homem possa ser livre das imposições da violência mítica? Trataremos a

\footnotetext{
11 "Todo conhecimento é culpa. Pelo menos todo conhecimento do bem ou mal - assim diz também a bíblia" Seria essa a tradução do texto alemão de BENJAMIN, Gesammelte Briefe, Band I, 19101918, Frankfurt am Main: Suhrkamp, 1995, p. 159.

12 "Sobre a linguagem em geral e a linguagem dos homens" in:_BENJAMIN - Escritos sobre mito e linguagem, p. 69.
} 
seguir, da tentativa de Benjamin de quebrar o círculo mítico da violência com a violência divina e os meios puros de violência, ou, podemos dizer, meios não violentos. Diz Benjamin:

\begin{abstract}
Longe de inaugurar uma esfera mais pura, a manifestação mítica da violência imediata mostra-se, em seu núcleo mais profundo, idêntica a toda violência do direito, e transforma a suspeita quanto ao caráter problemático dessa violência em certeza quanto ao caráter pernicioso de sua função histórica, tornando tarefa sua abolição. Tal tarefa suscita, em última instância, mais uma vez, a questão de uma violência pura, imediata, que possa estancar a marcha da violência mítica. ${ }^{13}$
\end{abstract}

\title{
OS MEIOS PUROS E O PODER DIVINO
}

A pergunta por uma solução não violenta dos conflitos humanos pode ser resolvida através dos meios puros, esses são não violentos. Já percebemos que a violência, quando não pura, desemboca em Direito, porém, os meios puros não invocam a força violenta do mito sobre os indivíduos, mas estabelece relações onde o arquétipo é desnecessário. $O$ apelo aos sentimentos humanos, aos laços afetivos, como o amor à paz, confiança, inclinação do coração e tudo aquilo que busca resolução de conflitos, sem instaurar e manter poder sobre os outros, pode ser caracterizado como meio puro. Daí se segue uma diferença crucial entre meios violentos e meios puros. Enquanto o primeiro busca resolução imediata, o segundo é mediato por resolver sem violência e usar a via das coisas materiais.

Os meios puros, pela característica da mediatidade só podem ser encontrados nas relações de homens particulares. Isso acontece porque em uma escala social a educação não violenta levaria um dispêndio de tempo que a sociedade acha não dispor. A sociedade, quando indefesa nas mãos da violência fora da jurisdição do Direito estabelecido, clama pelo aumento e utilização da violência institucionalizada da corporação policial nas ruas. Esse é um caso de violência do Direito de caráter imediato, assim como a deusa Leto no mito de Níobe, ao ser ameaçada, necessita manifestar sua existência e fundar um direito. Ao contrário do exemplo de penitência exigida pelo mito, apenas o uso de um meio puro, digamos aqui, a educação ${ }^{14}$, poderia ser um meio efetivo contra a violência

\footnotetext{
${ }^{13}$ BENJAMIN, 2011, p. 150.

${ }^{14}$ Devemos entender a educação, aqui, não como o atual sistema educacional formador de mão de obra do mercado de trabalho, mas uma educação baseada nos princípios da vida humana, onde o homem é livre e usa de meios puros para resolver seus problemas sem dominação sobre outros
} 
instauradora do mito. É enganoso acreditar que o aumento da violência estatal possa trazer uma solução imediata, pois apenas um processo educacional, meio mediato, resolveria o problema, porém, ele traz resultados a longo prazo. Mas ainda assim há quem prefira o aparente do mito do Direito à efetividade dos meios puros.

Os meios puros são os meios de rompimento com a violência mítica do Direito. No entanto, como apresentado acima, eles não possuem um efeito imediato e não são preferíveis por parte da sociedade frente ao Direito. Mas o fato de que há preferência do Direito, significa que a sociedade não tem compreensão da amarra mítica e da ambiguidade contida nele mesmo, sim, pois o Direito cria as forças violentas que irão derrubá-lo e se enfraquece sem a percepção disso.

\begin{abstract}
A existência das leis e da polícia é um atestado do fracasso da civilização, ou do seu sucesso, porque não podia ser outra coisa. Nada ameaça mudar realmente porque todos têm medo de que algo Ihes seja tomado. A coerção legal, que o cidadão aceita, foi criada porque já previram que, inevitavelmente, ela mesma seria desafiada. Ela não é defensiva nem preventiva. Ela é o primeiro ato de violência fundador, que desencadeou a violência mais ou menos generalizada e mais ou menos controlada que justifica sua estrutura e move seu mecanismo. ${ }^{15}$
\end{abstract}

A violência do Direito sabota o próprio Direito, porque não abrange a todos os homens de forma benéfica. Ela privilegia um grupo de poderosos e exclui aqueles que não fazem parte desse grupo e origina sua própria ruina. Gera a violência necessária para cair diante de uma contraviolência. O ciclo do Direito está traçado mais uma vez e continuará. Devido ao caráter imediato da violência mítica e o não imediato dos meios puros, devemos procurar uma violência pura de caráter imediato que interrompa a marcha da violência do Direito. Tal conceito é chamado por Benjamin de violência divina.

Se a violência mítica é instauradora do direito, a violência divina é aniquiladora do direito; se a primeira estabelece fronteiras, a segunda aniquila sem limites; se a violência mítica traz, simultaneamente, culpa e expiação, a violência divina expia a culpa; se a primeira é ameaçadora, a segunda golpeia; se a primeira é sangrenta, a divina é letal de maneira não sangrenta. ${ }^{16}$

homens. Dessa forma a educação, que advém do poder divino, atua sobre o ser humano através de sua própria existência, isto é,transforma-se aqui na própria vida.

${ }_{15}^{15}$ NETO, 2012, p. 166.

${ }^{16}$ BENJAMIN, 2011, p. 150.

Edson Sá dos Reis - Graduação em Filosofia pela Universidade Estadual do Ceará (UECE), Brasileiro, residente em Fortaleza - CE, E-mail: uchiha_edson16@hotmail.com 
A violência divina é aniquiladora de todo o Direito, pois ela não privilegia um grupo e exclui outros, e pode ser caracterizada como justiça. Ela não possui fronteiras, pois age sobre todos os seres vivos e se desenrola no palco da vida. $A$ violência divina não traz a culpa e a expiação inerente ao Direito, antes, expia a culpa do homem. Sob a luz da violência divina, os pressupostos de culpa e ameaça não possuem nenhuma validade, pois o palco de atuação dela é a vida. Nesse palco, a violência divina não põe no homem esses fatores presentes no Direito e muito menos reduz o homem à mera vida. Enquanto o direito remete a uma culpa inerente à mera vida, a violência divina expia o culpado e o liberta do Direito.

A violência mítica é violência sangrenta exercida, em favor próprio, contra a mera vida; a violência divina e pura se exerce contra toda a vida, em favor do vivente. A primeira exige sacrifícios, a segunda os aceita. ${ }^{17}$

A violência mítica exerce o domínio sobre a existência do homem transformando-a em mera vida, porém, o poder divino liberta o homem da mera vida e absolve sua culpa para que ele viva. O poder divino se exerce sobre toda a vida igualando todos os homens. Essa ocorre nos "momentos de cumprimento nãosangrento, golpeador, expiador de culpa." 18 Dessa maneira não há qualquer instauração do Direito. A violência ou o poder divino se estabelece em todos os segmentos da vida, porém, ela não aniquila a alma do vivente, mas "é insígnia e chancela". A violência divina está presente na própria existência e como demonstrado, pode ser encontrada nos momentos onde não existe a violência instauradora do Direito: "O saber que emana do poder divino é capaz de (...) libertar o outro de seu destino, absolvendo-o (...) em contraponto ao conhecimento do direito de julgar do sistema jurídico". ${ }^{19}$

Em síntese, toda a história da luta dos homens pode ser traçada com o propósito de estabelecimento do Direito, porém, estancar a marcha do mito é possível a partir de uma análise da violência mítica. Benjamin atentou ao mito criado na linguagem e nas formas que o mesmo assume a partir do "ato judicante" dentro da sociedade e dessa forma podemos ter uma ideia de seu domínio exercido sobre

\footnotetext{
${ }^{17}$ BENJAMIN, 2011, p. 151-152.

18 BENJAMIN, 2011, p. 152.

${ }^{19}$ CALLADO, Tereza de Castro, "Da Sacralidade barroca à iluminação profana do pensamento" in: Cadernos Walter Benjamin n. 09 julho-Dezembro de 2012, Edição eletrônica: www.gewebe.com.br
} 
a vida humana. A violência divina articulada em Benjamin demonstra uma de suas tentativas de quebra do movimento mítico do Direito em torno da vida do homem. É também tentativa da quebra da linguagem judicante explicado no ensaio Sobre a linguagem em geral e a linguagem dos homens, de 1916, que classifica e prende a natureza, porém, no ensaio de 1921 Para uma crítica da violência (Zur Kritik der Gewalt), é a libertação da vida humana do jugo do Direito que está em jogo. É o homem contra as amarras daquilo que ele chama de mera vida e dos conceitos de culpa e sua ameaça, enraizados tradicionalmente em nossa sociedade.

Devemos trazer a discussão em pauta, pois as reflexões de Benjamin mostram-se extremamente válidas para nós, atualmente. Porém, o problema sobre o Direito e a sua distância da justiça permanece obscuro, pois não podemos delinear o que seria justiça e nosso filósofo não busca um tal significado, senão dentro de possibilidades livres, onde justiça não é uma palavra presa a um único significado. Como sempre, ele nos faz refletir sobre as múltiplas formas em que a justiça pode aparecer. O filósofo deixa entrever que ela está em todos os momentos da vida e cabe a nós procurá-la e responder a ela, a partir da própria existência. 


\section{REFERÊNCIAS}

BENJAMIN, Walter. "Para uma crítica da violência” in: "Sobre a linguagem em geral e a linguagem dos homens" in: Escritos sobre mito e linguagem (1915-1921) Organização, apresentação e notas de Jeanne Marie Gagnebin; tradução de Susana Kampff Lages e Ernani Chaves - São Paulo: Duas cidades; Editora 34, 2013 (2ํㅜㄴ edição).

BENJAMIN, Walter. "Sobre a Crítica do poder como violência" in__ $\mathbf{0}$ anjo da história / Walter Benjamin ; Organização e tradução de João Barrento - Belo Horizonte : Autêntica Editora, 2012. - (Filô/Benjamin).

BENJAMIN, Walter. "Drama Barroco e Tragédia", "O Significado da Linguagem no Drama Barroco e na Tragédia" in: O capitalismo como religião/ Walter Benjamin, Organização de Michael Löwy: tradução Nélio Schneider, Renato Ribeiro Pompeu]. - 1. Ed. - São Paulo: Boitempo, 2013.

CALLADO, Tereza de Castro. "Da Sacralidade Barroca à Iluminação Profana do Pensamento; ensaio sobre linguagem, política e estado de criação" in:_Cadernos Walter Benjamin n.09 - Revista Eletrônica - Julho-Dezembro de 2012. www.gewebe.com.br.

DERRIDA, Jacques. Força de Lei - O fundamento místico da autoridade, tradução de Fernanda Bernardo, Porto: Campo das Letras, 2003.

SOREL, George, Ensaio sobre a Violência, Tradução de Orlando dos Reis. Petrópolis , RJ : Vozes, 1993.

NETO, Airton Uchoa. Crônica da província em chamas/ Airton Uchoa Neto. Fortaleza: La Barca, 2012. 